\title{
Atrial flutter in the fetus and young infant: an association with accessory connections
}

\author{
Janice Till, Christopher Wren
}

\begin{abstract}
Objective-To highlight the association between atrial flutter and accessory connections in the fetus and young infant.

Design-A retrospective review from January 1985 to January 1990.

Patients-Fetuses, neonates, and young infants with atrial flutter.

Results-Four fetuses and five infants presented with atrial flutter. In two fetuses and one infant sinus rhythm returned spontaneously. The other six required cardioversion. Three of them developed orthodromic atrioventricular re-entry tachycardia and each had evidence of an accessory connection.

Conclusions-Because atrial flutter in the fetus and neonate is rare, the high incidence of accessory connections in this group points to a possible aetiology of "idiopathic" atrial flutter in this age group.
\end{abstract}

Atrial flutter is an uncommon arrhythmia in the fetus, the neonate, and in infancy. Associated structural heart disease is unusual and most cases are considered to be idiopathic. In a five year period we encountered nine patients with atrial flutter presenting in fetal life or early infancy. Given the rarity of atrial flutter in this age group, the finding of accessory connections in three patients $(33 \%)$ is likely to be of aetiological significance.

\section{Patients and methods}

From January 1985 to January 1990 we encountered nine patients with atrial flutter presenting in fetal life or early infancy. The diagnosis of atrial flutter in the fetus was made echocardiographically from the finding of a regular atrial tachycardia (rate $400-500$ beats per minute) with atrioventricular block (generally $2: 1){ }^{1}$ The diagnosis of atrial flutter in the newborn was made in the presence of characteristic flutter waves on the surface electrocardiogram at $300-500$ per minute with atrioventricular block. Evidence of preexcitation was sought on all electrocardiograms, especially those recorded in sinus rhythm, but no provocative tests (such as vagal stimulation, intravenous adenosine, or oesophageal pacing) were used to unmask latent pre-excitation or in an attempt to induce tachycardia.

\section{Results}

Nine patients with atrial flutter were identified. The table gives their clinical characteristics.
Two of the four patients presenting in utero reverted to sinus rhythm before birth and none of the four had evidence of pre-excitation on postnatal electrocardiograms. Six of seven patients with atrial flutter present at birth or soon afterwards had a sustained arrhythmia and required direct current cardioversion. There was no recurrence of flutter in any patient but three developed sustained orthodromic atrioventricular re-entry tachycardia and all three had evidence of an accessory connection.

Patient 3 was identified as having atrial flutter in utero at 36 weeks' gestation. Atrial flutter was still present at birth at term. The electrocardiogram confirmed the diagnosis of atrial flutter with an atrial rate of 420 per minute and 2:1 atrioventricular conduction but showed no evidence of pre-excitation (fig 1A). Atrial flutter persisted for 24 hours when direct current cardioversion was performed. A single shock of $5 \mathrm{~J}$ restored sinus rhythm for a few beats before sustained narrow QRS tachycardia at 300 beats per minute developed. A further shock again restored sinus rhythm transiently but tachycardia resumed almost immediately. The QRS complexes at the onset of tachycardia showed a left bundle branch block pattern. Spontaneous resolution of the bundle branch block was associated with a decrease in cycle length from 260 to $235 \mathrm{~ms}$, supporting the diagnosis of atrioventricular reentry tachycardia with a concealed left accessory pathway (fig 1B-D). Recordings in sinus rhythm showed no evidence of pre-excitation. The arrhythmia was difficult to control but was eventually suppressed by treatment with oral flecainide. There were occasional recurrences of orthodromic atrioventricular re-entry tachycardia over the first 18 months of life but no recurrence of atrial flutter.

Patient 7 was noted to have tachycardia during labour. An electrocardiogram after delivery showed atrial flutter of 400 beats per minute with variable atrioventricular block (fig $2 A)$. The ventricular rate ranged from 160 to 190 beats per minute. The baby remained well and was treated with digoxin from nine days of age to control the ventricular rate. At 14 days of age he developed a wide QRS tachycardia with a ventricular rate of 200 per minute which was interpreted as atrial flutter with pre-excitation via an accessory connection (fig $2 \mathrm{~B}$ ). Treatment with digoxin was stopped and a direct current shock restored sinus rhythm. The electrocardiogram then showed Wolff-Parkinson-White syndrome and the pattern of pre-excitation was consistent with a left posterior accessory 
Clinical details of nine fetuses and infants with atrial flutter

\begin{tabular}{|c|c|c|c|c|c|c|c|}
\hline Patient & Sex & $\begin{array}{l}\text { Age at } \\
\text { presentation (wk) }\end{array}$ & $\begin{array}{l}\text { Atrial } \\
\text { rate (per min) }\end{array}$ & $\begin{array}{l}\text { Ventricular } \\
\text { rate (per min) }\end{array}$ & $\begin{array}{l}\text { Maternal } \\
\text { drugs }\end{array}$ & $\begin{array}{l}\text { Rhythm } \\
\text { at birth }\end{array}$ & Comments \\
\hline $\begin{array}{l}1 \\
2 \\
3 \\
4 \\
5 \\
6 \\
7 \\
8 \\
9\end{array}$ & $\begin{array}{l}\mathbf{F} \\
\mathbf{F} \\
\mathbf{M} \\
\mathbf{M} \\
\mathbf{M} \\
\mathbf{M} \\
\mathbf{M} \\
\mathbf{F} \\
\mathbf{F}\end{array}$ & $\begin{array}{l}40^{\star} \\
40^{\star} \\
40^{\star} \\
40^{\star} \\
\text { Birth } \\
\text { Birth } \\
\text { Birth } \\
\text { Birth } \\
7 \text { wk }\end{array}$ & $\begin{array}{l}420 \\
420 \\
410 \\
420 \\
374 \\
400 \\
400 \\
300 \\
360\end{array}$ & $\begin{array}{l}210 \\
210 \\
205 \\
210 \\
130-300 \\
200 \\
160-190 \\
300 \\
180\end{array}$ & $\begin{array}{l}\text { Digoxin } \\
\text { Digoxin } \\
\text { Digoxin } \\
\text { Digoxin }\end{array}$ & $\begin{array}{l}\text { SR } \\
\text { AFL } \\
\text { AFL } \\
\text { SR } \\
\text { AFL } \\
\text { AFL } \\
\text { AFL } \\
\text { AFL } \\
?\end{array}$ & $\begin{array}{l}\text { Concealed accessory pathway } \\
\text { Wolff-Parkinson-White syndrome } \\
\text { Wolff-Parkinson-White syndrome }\end{array}$ \\
\hline
\end{tabular}

^Diagnosed in utero.

SR, sinus rhythm; AFL, atrial flutter.

\section{Figure 1}

Electrocardiograms from patient 3. Recordings show atrial flutter with $2: 1$ atrioventricular

conduction $(A)$, onset of

tachycardia with left

bundle branch block

pattern $(B)$, resolution of

bundle branch block with

shortening of tachycardia

cycle length $(C)$, and

termination of tachycardia

with no evidence of pre-

excitation in sinus rhythm

(D). Panel $A$ is lead I and

Panels $B, C$, and $D$ are

lead II.

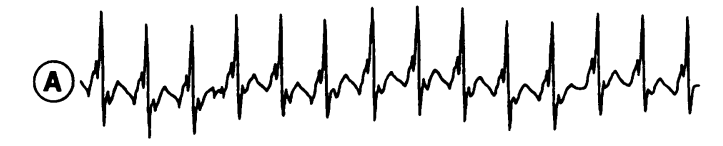

(B)

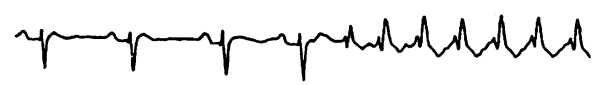

(c)

(D) prppeppeppraps

(B)

(C)

(D)

I) (A)

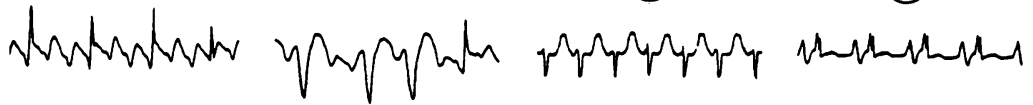

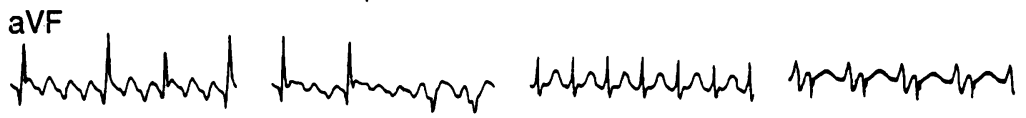

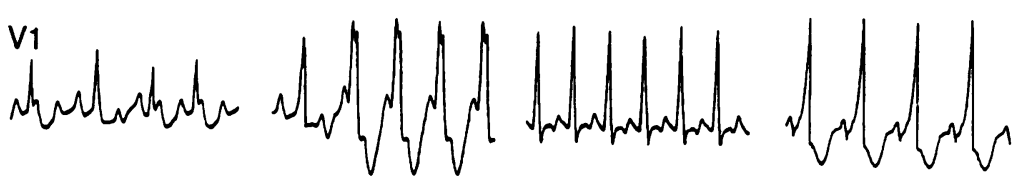

$1 \mathrm{mV}$

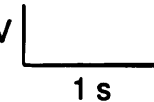

Figure 2 Electrocardiograms from patient 7. Leads II, aVF, and VI are shown with recordings at birth $(A)$, after treatment with digoxin showing pre-excitation $(B)$, in orthodromic atrioventricular re-entry tachycardia (C), and in sinus rhythm showing evidence of Wolff-Parkinson-White syndrome $(D)$.

orthdromic atrioventricular re-entry with a narrow QRS over the next 12 hours were terminated with intravenous adenosine (fig 2C). Initially tachycardia was suppressed with oral flecainide but after 36 hours incessant atrioventricular re-entry at 214 beats per minute developed. Flecainide was stopped and replaced by amiodarone. There has been no recurrence of atrioventricular tachycardia nor of atrial flutter on this treatment.

Patient 9 presented aged seven weeks with heart failure. She had had symptoms from birth and her weight had fallen from the 97th centile to the $3 \mathrm{rd}$, so that at presentation she was below her birth weight. An electrocardiogram showed atrial flutter with $2: 1$ conduction (fig 3A). Observation showed intermittent pre-excitation with a delta wave present for about 30 seconds (fig 3B) followed by normal conduction for 30 seconds. Electrical cardioversion restored sinus rhythm and the electrocardiogram then showed a delta wave with the pattern of pre-excitation suggesting a posteroseptal accessory pathway (fig 3D). Within 15 minutes the baby developed a narrow $Q R S$ tachycardia at 300 per minute (fig 3C). Adenosine restored sinus rhythm on three occasions and the fourth episode was treated with intravenous flecainide. This was followed by oral flecainide and there has been no recurrence of atrial flutter or orthodromic atrioventricular re-entry in 12 months of follow-up.

\section{Discussion}

Sustained tachycardia in the newborn is uncommon and at this stage atrial flutter occurs much less frequently than supraventricular tachycardia. Both arrhythmias also occur in the fetus but flutter is then proportionately more common. ${ }^{2}$ Compared with older children very few fetuses or infants with atrial flutter have associated structural heart disease and the arrhythmia is usually considered to be idiopathic. $^{3}$ The three cases we describe showed the typical electrocardiographic features of atrial flutter in this age group. The new born atria differ from those in the adult in their ability to sustain high flutter rates which may exceed 400 per minute.

The presence of accessory connections in three of our nine patients, all with sustained atrioventricular re-entry tachycardia after treatment of the atrial flutter, is intriguing and is likely to be of aetiological importance. The association of atrial flutter and accessory connections in the fetus and the newborn has been reported occasionally but its significance has probably not been fully appreciated. Lubbers et al reported eight infants with atrial flutter, two of whom had Wolff-Parkinson-White syndrome. ${ }^{4}$ Rowland et al reported seven cases of atrial flutter (two in the fetus and five in the newborn) with one case of recurrent paroxysmal supraventricular tachycardia probably due to an accessory connection. ${ }^{5}$ Chantepie et al documented atrial flutter, rapid atrial tachycardia, and orthodromic atrioventricular re-entry tachycardia in a premature baby with WolffParkinson-White syndrome. ${ }^{6}$ Belhassen et al described a baby with Wolff-Parkinson-White 
(A)<smiles>CC(C)N(C)NCCN</smiles>

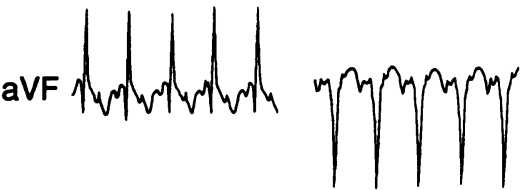
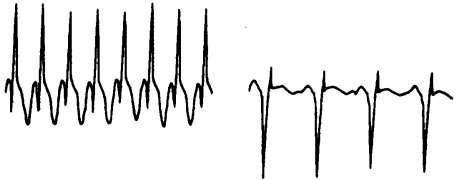

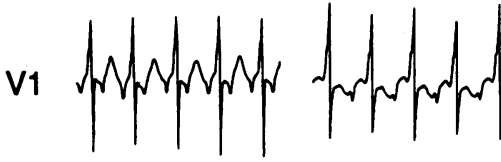
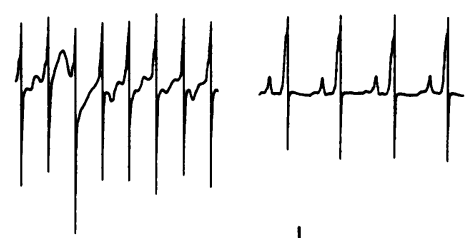

$1 \mathrm{mV}$

$1 \mathrm{~s}$

Figure 3 Electrocardiograms from patient 9. Leads I, aVF, and V1 are shown. Recordings were taken at presentation in atrial flutter with $2: 1$ atrioventricular conduction without $(A)$ and with pre-excitation $(B)$, after cardioversion showing orthodromic atrioventricular re-entry tachycardia (C), and in sinus rhythm showing evidence of Wolff-Parkinson-White syndrome $(D)$.

syndrome and atrial flutter documented in utero and postnatally. ${ }^{7}$ Meha et al described a baby born at 36 weeks' gestation by emergency caesarean section for fetal tachycardia. ${ }^{8}$ They observed atrial flutter with intermittent $1: 1$ anterograde conduction over an accessory connection and "atrial fibrillation", which in retrospect seems more likely to have been atrial flutter with variable atrioventricular block after the administration of digoxin, lignocaine and phenytoin. Johnson et al reported a case in which fetal supraventricular tachycardia at 26 weeks' and atrial flutter at 27 weeks' gestation were confirmed echocardiographically. ${ }^{9}$ Sinus rhythm resumed after maternal treatment with quinidine. A postnatal tranoesophageal electrophysiological study confirmed the presence of a left lateral accessory connection. Maxwell et al described 23 cases of fetal tachycardia; 12 supraventricuar tachycardia, eight atrial flutter, and three in which the rhythm varied between supraventricular tachycardia and atrial flutter. ${ }^{2}$ No details of the postnatal electrocardiograms were given. Deal et al, in a report of 90 infants with Wolff-ParkinsonWhite syndrome, found one born with atrial flutter who developed a wide QRS tachycardia on digoxin, similar to patient 7 in our series. ${ }^{10}$ Dunnigan et al, Martin and Hernandez, and Moller et al between them reported 24 cases of atrial flutter with no evidence of accessory connections. ${ }^{11-13}$

The underlying cause of atrial flutter in the fetus and the newborn is unknown. The association of atrial flutter and atrioventricular re-entry tachycardia via an accessory connection in our cases and in the reports above is interesting and may be of aetiological importance, given the rarity of atrial flutter in this situation. In adults the association between atrial flutter and accessory connection arrhythmias is well recognised. Episodes of sustained atrioventricular re-entry tachycardia have been reported to revert directly to atrial flutter. ${ }^{14}$ The occurrence of atrial flutter in the fetus or the neonate with an accessory connection may represent a similar phenomenon. The reason for the degeneration of atrioventricular reentry tachycardia into atrial flutter or fibrillation is not clear but the occurrence of an atrial extra-stimulus during the atrial vulnerable period may play a part. Atrioventricular reentry tachycardia in the fetus or newborn often impairs cardiac function and may cause appreciable atrial dilatation. This may facilitate the initiation and maintenance of atrial flutter which, with its shorter cycle length, would then become the dominant rhythm. A further theoretical mechanism is the possible retrograde conduction of ventricular extrasystoles to the atrium via the accessory connection which might initiate atrial flutter. ${ }^{15}$

The electrophysiological characteristics of the heart change rapidly from the fetus to the neonate and during the first year of life, although the full extent of these changes is unknown. The different rates of atrioventricular re-entry tachycardia in the fetus and the neonate are well recognised, as are changes with age in the conduction characteristics and refractory periods of accessory pathways. ${ }^{1617}$ Such changes may underlie the difference in the relative incidence of atrial flutter and atrioventricular re-entry tachycardia in the fetus, the neonate, and the infant and may explain the dramatic reduction in the occurrence of isolated atrial flutter with increasing age and maturity in early life. Cessation of spontaneous recurrences of supraventricular tachycardia and of pre-excitation in the newborn with Wolff-Parkinson-White syndrome is common. ${ }^{18}$ Disappearance, whether functional or physical, of accessory connections during fetal life is probably also common, so that there may be no evidence of an accessory connection once sinus rhythm is restored after birth.

This association may have implications for management. Historically digoxin has been used as the drug of first choice for flutter in young children. ${ }^{513}$ The action of digoxin on atrial cells is to shorten the refractory period, an action which theoretically would enhance the chances of atrial flutter being sustained rather than bring about its termination, although it may decrease the ventricular rate by slowing atrioventricular node conduction. The use of digoxin in atrial flutter with an accessory connection is more controversial as it is known that digoxin may decrease the anterograde refractory period of the accessory connection, thus allowing more atrial impulses to reach the ventricle-a potentially life-threatening situation. We feel, therefore, that digoxin should not be the drug of first choice in this situation and recommend direct current cardioversion or overdrive atrial pacing in preference.

1 Allan LD, Anderson RH, Sullivan ID, Campbell S, Holt llan LD, Anderson RH, Sullivan ID, Campbell S, Holt DW, Tynan M. Evaluation of fetal arrhy

2 Maxwell DJ, Crawford D, Curry PVM, Tynan MJ, Allan LD. Obstetric importance, diagnosis, and management of 
fetal tachycardias. $B M J$ 1988;297:107-10

3 Garson A, Bink-Boelkens $M$, Hesslein PS, Hordof AJ, Keane KF, Neches WH, et al. Atrial flutter in the young: collaborative study of 380 cases. J Am Coll Cardio 1985;6:871-8.

4 Lubbers WJ, Losekoot TG, Anderson RH, Wellens HJJ. Paroxysmal supraventricular tachycardia in infancy and childhood. Eur J Cardiol 1974;2:91-9.

5 Rowland TW, Matthew R, Chameides L, Keane JF Idiopathic atrial flutter in infancy: a review of eight cases. Pediatrics 1978;61:52-6.

6 Chantepie A, Ramponi N, Vaillant MC, Laugier J, Raynaud P, Fauchier JP. Tachycardie auriculaire polymorphe et syndrome de Wolff-Parkinson-White chez le nouveau-né. Arch Mal Coeur 1986;9:1371-5.

7 Belhassen B, Pauzner D, Blieden L, Sherez J, Zinger A, David $M$, et al Intrauterine and postnatal atrial fibrillation in the Wolff-Parkinson-White syndrome. Circulation 1982;66:1124-8

8 Mehta AV, Pickoff AS, Raptoulis A, Wolff GS, Garcia OL Tamer DF, et al Atrial flutter and atrial fibrillation associated with Wolff-Parkinson-White syndrome in childhood. Pediatr Cardiol 1980;1:197-202.

9 Johnson WH, Dunnigan A, Fehr P, Benson DW. Association of atrial flutter with orthodromic reciprocating fetal tachycardia. Am J Cardiol 1987;59:374-5.

10 Deal BJ, Keane JF, Gillette PC, Garson A Jr. WolffParkinson-White syndrome and supraventricular tachy- cardia during infancy: management and follow-up. $\mathrm{J} \mathrm{Am}$ Coll Cardiol 1985;5:130-5.

11 Dunnigan A, Benson DW Jr, Benditt DG. Atrial flutter in infancy: diagnosis, clinical features and treatment. Pediatrics 1985;75:725-9.

12 Martin TC, Hernandez A. Atrial flutter in infancy. Pediatrics 1982;100:239-41.

13 Moller JH, Davachi F, Anderson RC. Atrial flutter in infancy. J Pediatr 1969;75:643-51.

14 Sung RJ, Castellanos A, Mallon SM, Bloom MG, Gelband $\mathrm{H}$, Myerberg RJ. Mechanisms of spontaneous alteration between reciprocating tachycardia and atrial flutterfibrillation in the Wolff-Parkinson-White syndrome. Circulation 1977;56:409-16.

15 Fujimura O, Klein GJ, Yee R, Sharma AD. Mode of onset of atrial fibrillation in the Wolff-Parkinson-White synatrial fibrillation in the Wolff-Parkinson-White syn-
drome: how important is the accessory pathway? $\mathrm{J} \mathrm{Am}$ Coll Cardiol 1990;15:1082-6.

16 Zales VR, Dunnigan A, Benson DW Jr. Clinical and electrophysiologic features of fetal and neonatal paroxysmal atrial tachycardia resulting in congestive heart failure. Am J Cardiol 1988;62:225-8.

17 Benson DW Jr, Dunnigan A, Benditt DG. Follow-up evaluation of infant paroxysmal atrial tachycardia: transesophageal study. Circulation 1987;75:542-9. 18 Dunnigan A, Benditt DG, Benson DW Jr. Modes of onset infants and children. Am J Cardiol 1986;57:1280-7. 